\title{
Identifying alterations in metabolic profiles of dairy cows over the past two decades in Japan using principal component analysis
}

\author{
M. Kayano*† and K. Kida† ${ }^{1}$ \\ ${ }^{*}$ Global Agro-Medicine Research Center, and \\ †Field Center of Animal Science and Agriculture, Obihiro University of Agriculture and Veterinary Medicine, Inada-Cho, Obihiro, \\ Hokkaido 080-8555, Japan
}

\begin{abstract}
The aim of this study was to identify the metabolic changes that have occurred in Holstein-Friesian cows in Japan over the past 2 decades, based on long-term metabolic profiles. From 1987 to 2004, metabolic profile tests were conducted in 1,700 dairy herds containing $\sim 50,000$ cows. The cows were divided into 5 lactation stage groups: early (calving to $49 \mathrm{~d}$ in milk, DIM), peak (50-109 DIM), mid (110-209 DIM), and late (210 to dry-off) lactation and the dry period. Principal component analysis was applied to the metabolic profiles at each lactation stage separately to investigate changes in metabolic profiles across the multiyear periods 19871992, 1993-1998, and 1999-2004. We determined that cows have probably experienced increasing negative energy balance, energy deficiency, and liver dysfunction during the past 2 decades in Japan.
\end{abstract}

Key words: blood enzyme, blood metabolite, energy balance, liver dysfunction

\section{INTRODUCTION}

Because of the genetic improvement of dairy cows, annual milk yield has increased by more than 2,000 $\mathrm{kg} /$ cow over the past 2 decades in Japan (Statistics information, Ministry of Agriculture, Forestry and Fisheries of Japan; MAFF). This implies an increase in daily milk production of more than $10 \mathrm{~kg} /$ cow and DMI of more than $4 \mathrm{~kg} / \mathrm{d}$ (NRC, 2001). However, the calving interval of dairy cows increased from 402 to 431 d in Japan from 1987 to 2006 (Livestock Improvement Association of Japan, LIAJ, Tokyo, Japan), and the conception rate at the first AI decreased from 59.1 to 49.7\%, in Hokkaido, Japan, from 1987 to 2004 (Hokkaido Artificial Insemination Technician Association Inc., Hokkaido, Japan). The physiological status of

Received May 7, 2015.

Accepted August 26, 2015.

${ }^{1}$ Corresponding author: kidak@obihiro.ac.jp dairy cows has also changed during the past 2 decades: for example, it is well known that the concentration of total serum cholesterol usually changes according to milk yield (Kaneko, 1989; Kida, 2003), and elevated free fatty acid content indicates a negative energy balance, which can be a cause of low fertility (Butler and Smith, 1989; Butler, 2005) in high-producing dairy cows.

The metabolic profile test (MPT) is a well-known method for evaluating the nutritional status of dairy cows (Payne et al., 1970; Payne, 1972; Lee et al., 1978; Rowlands, 1984; Eicher, 2003). Many applications exist for using MPT as a herd-screening tool (Adams et al., 1978; Kida, 2002b, 2003; Macrae et al., 2006) and for assessing disease conditions (Kudlác et al., 1995; Kida, 2002a; Holtenius et al., 2004; Stengärde et al., 2008). In particular, Kida (2002a,b, 2003) demonstrated the application of long-term MPT in Japan. In the current study, we applied principal component analysis (PCA) to a long-term MPT database that we compiled in Japan over the past 2 decades. The aim of applying PCA was to clarify the metabolic changes in HolsteinFriesian cows both statistically and visually.

\section{MATERIALS AND METHODS}

\section{Study Population and Data Collection}

From 1987 to 2004, MPT were conducted on 49,569 cows (average parity: $3.0 \pm 1.5$, range of 1 to 10 ) in 1,700 dairy herds in Hokkaido, Japan. The MPT was conducted as follows. Five to 6 apparently healthy cows were selected from each of 4 lactation stages and the dry period on each farm. The lactation stages were defined as early (calving to 49 DIM), peak (50-109 DIM), mid (110-209 DIM), and late (210 DIM to dryoff) lactation. Blood samples were collected from the jugular vein between 0900 and $1100 \mathrm{~h}$, and 14 blood components (Table 1) were measured by automatic analyzers [VP-Super(R), Abbott Co. Ltd. (Chicago, IL) and TBA 70-R(R), Toshiba (Tokyo, Japan)]. This study focused on 12 components: hematocrit (HT, \%), $\gamma$-glutamyl transferase (GGT, IU), aspartate amino 
Table 1. The 14 blood components analyzed in the metabolic profile test

\begin{tabular}{ll}
\hline Abbreviation & Description \\
\hline HT & Hematocrit \\
GGT & Gamma-glutamyl transferase \\
AST & Aspartate amino transferase \\
BUN & Blood urea nitrogen \\
GLU & Blood glucose \\
IP & Inorganic phosphate \\
T-CHOL & Total cholesterol \\
F-CHOL & Free cholesterol \\
Mg & Magnesium \\
NEFA & Nonesterified fatty acid \\
Ca & Calcium \\
TP ${ }^{1,2}$ & Total protein \\
ALB & Albumin \\
GLOB & Globulin (TP - ALB)
\end{tabular}

${ }^{1}$ Not studied in our analysis.

${ }^{2}$ Total protein was used only for showing yearly change of protein in Figures A1, A2, and A3.

transferase (AST, IU), BUN (mg/dL), blood glucose level (GLU, mg/dL), inorganic phosphate (IP, mg/ $\mathrm{dL}$ ), total cholesterol (T-CHOL, mg/dL), Mg (mg/ $\mathrm{dL})$, NEFA $(\mu \mathrm{Eq} / \mathrm{L}), \mathrm{Ca}(\mathrm{mg} / \mathrm{dL})$, albumin (ALB, $\mathrm{g} / \mathrm{dL}$ ), and globulin (GLOB, g/dL). Indicators used to evaluate (1) protein, (2) energy metabolism, (3) liver function, and (4) mineral metabolism were (1) HT, BUN, ALB, and GLOB; (2) GLU, T-CHOL, and NEFA; (3) AST and GGT, and (4) Ca, IP, and Mg, respectively (e.g., Payne and Payne, 1987; Kida, 2002a).

In this study, we investigated changes in the metabolic profile at each lactation stage across 3 multiyear periods: 1987-1992, 1993-1998, and 1999-2004. The cows were allotted into 3 and 5 groups based on period and lactation stage, respectively.

\section{Statistical Analysis 1: Summary and Descriptive Statistics}

We first removed data for individual cows that included outliers or missing values, according to the procedure below: (1) data for cows that had missing values for at least one component were removed ; $(2)$ for each component, the following procedure was repeated up to 3 times: cows outside the range of mean $\pm 3 \mathrm{SD}$ for that component were excluded. Procedures (1) and (2) removed 2,440 and 4,923 cows from the original data set, respectively. The remaining data set included 42,206 cows, which were utilized in the analyses in this study. Tables 2 and 3 summarize the number of cows, milk yield $(\mathrm{kg} / \mathrm{d})$, and average age (mo) of the cows in each period and lactation stage group. The mean value of the 12 components in each year and lactation stage was summarized in a table. The early and peak lactation stages and dry period were the main focus in this study, because these 3 stages are important in dairy cattle performance; in addition, change in milk yield in mid and late lactation were related to that at early and peak lactation stages among 3 multiyear periods. Yearly boxplots of milk yield, AST, NEFA, and TP at peak lactation stage are shown in the Appendix.

\section{Statistical Analysis 2: PCA}

Principal component analysis is a dimension-reduction technique for multivariate data. For metabolic profile data in this study, PCA summarized the $12 \mathrm{com}-$ ponents into a few scores (i.e., principal components, PC) by summation of the components: for example, the first score (PC1) may be given by $0.5 \mathrm{HT}+0.5$ GGT - 0.5 AST + 0.5 BUN, and the second score (PC2) may be obtained by $-0.5 \mathrm{GLU}-0.5 \mathrm{IP}+0.5 \mathrm{~T}$ $\mathrm{CHOL}+0.5 \mathrm{Mg}$, where the coefficients such as 0.5 and -0.5 (loadings) are important to interpret the meaning of each PC. Each PC may show a specific feature of cows such as negative energy balance or liver dysfunction according to how the PCA adds the components in each PC. A contribution rate of each $\mathrm{PC}$ in all 12 components can be evaluated in terms of variance; for example, when $\mathrm{PC} 1$ has variance of 30 out of 100 for all components, the contribution of PC1 in the 12 components is $30 \%$.

A PCA based on a correlation matrix was conducted on the metabolic profile data from each lactation stage separately. The use of a correlation matrix of the components relaxes the scale difference among the components to the result of PCA. The purpose of applying $\mathrm{PCA}$ is to investigate changes in metabolic profiles over time using summarized components; that is, PC. In

Table 2. The number of cows in each period and lactation stage group

\begin{tabular}{lrrrrrr}
\hline & \multicolumn{5}{c}{ Lactation stage } & \\
\cline { 2 - 5 } Period & Early & Peak & Mid & Late & Dry period & \multirow{2}{*}{ Total } \\
\hline $1987-1992$ & 1,452 & 2,387 & 3,748 & 3,307 & 1,257 & 12,151 \\
$1993-1998$ & 2,256 & 3,423 & 4,926 & 4,488 & 3,208 & 18,301 \\
$1999-2004$ & 1,436 & 2,217 & 3,091 & 2,983 & 2,027 & 11,754 \\
Total & 5,144 & 8,027 & 11,765 & 10,778 & 6,492 & 42,206 \\
\hline
\end{tabular}


Table 3. Summary of milk yield and age of cows (mean with SD in parentheses) in each period and lactation stage group

\begin{tabular}{lcccccc}
\hline & \multicolumn{9}{c}{ Lactation stage } & \\
\cline { 2 - 5 } Item and period & Early & Peak & Mid & Late & Dry period & Mean (SD) \\
\hline Milk yield (kg/d) & $34.6(8.4)$ & $35.2(8.6)$ & $29.7(7.6)$ & $22.5(6.8)$ & - & $29.2(9.2)$ \\
$\quad$ Total & $33.3(8.3)$ & $33.6(8.4)$ & $28.3(7.5)$ & $20.8(6.5)$ & - & $27.7(9.1)$ \\
$1987-1992$ & $35.0(8.5)$ & $35.7(8.5)$ & $30.2(7.6)$ & $22.9(6.6)$ & - & $29.8(9.2)$ \\
$1993-1998$ & $35.2(8.2)$ & $36.1(8.7)$ & $30.5(7.7)$ & $23.7(7.1)$ & - & $30.2(9.3)$ \\
$1999-2004$ & $52.7(24.1)$ & $54.7(24.4)$ & $57.3(23.8)$ & $59.9(23.6)$ & $61.5(23.4)$ & $57.5(24.0)$ \\
Age (mo) & & & & & &
\end{tabular}

examining the resulting PCA plots, we investigated the separateness of the PC among the multiyear periods. The Kruskal-Wallis test, that contains a $P$-value and a $\chi^{2}$ statistic, was carried out to test the significance of the differences among the multiyear periods. A large $\chi^{2}$ value provides a small $P$-value. We also calculated the effect (contribution) of each component to each PC by dividing the loading by the standard deviation of the component, because the PCA was based on the correlation matrix. All of the analyses were performed using statistical software $\mathrm{R}$ (version 2.14.0 for Macintosh; https://cran.r-project.org/bin/macosx/).

\section{RESULTS}

Table 4 summarizes the changes in the 12 components in each year and lactation stage. Indicators of energy metabolism (NEFA) and liver function (AST) increased across multiyear periods. Particularly, NEFA increased by approximately $60 \%$ in peak lactation and by $30 \%$ in early lactation and dry period from 1987 to 2004. Aspartate amino transferase increased by approximately $23 \%$ in all lactation stages. Slight differences were observed on the indicators of protein metabolism (BUN decreased by 12\%, ALB increased by $5 \%$, and GLOB increased by $8 \%$ ), energy metabolism (GLU increased by 1 to $3 \%$, and T-CHOL increased by $3 \%$ ), liver function (GGT increased by $5 \%$ ), and mineral metabolism (Ca decreased by $3 \%$, IP decreased by $10 \%$, and $\mathrm{Mg}$ decreased by $5 \%$ ).

Yearly boxplots of milk yield, AST, NEFA, and TP at peak lactation stage are shown in Figure A1 in the Appendix. These boxplots were used to determine how to divide the year period of 1987-2004. In fact, progeny tests were popularized in Japan around 1990; it makes sense to explain the difference of the yearly change of milk yield and the metabolites. Milk yield, AST, TP, and NEFA gradually changed during the 3 multiyear periods; for example, milk yield gradually increased during 1987-1992 and has stayed relatively high. Changes in some of the components were similar: AST and TP increased during 1993-1998 and stayed high, and NEFA increased during 1999-2004. These changes were also found in each calving of first, second, and $\geq$ third calvings (Figure A2 in Appendix). This implies that simultaneous analysis combining first, second, and $\geq$ third calvings would be effective to investigate yearly changes in the physiological state of dairy cows. The outliers that were excluded from the data set did not affect yearly changes in AST, NEFA, or TP (Figure A3 in Appendix). If the outliers affected yearly change, we would lose information on unhealthy cows, which might have an important role in a study physiological change (e.g., show a high NEFA).

Table 5 summarizes the first $4 \mathrm{PC}$ in the early and peak lactation stages and dry period. The 4 PC had approximately $50 \%$ of the total variation explained by the 12 components at all stages. The second and third $\mathrm{PC}$ were much different among multiyear periods at all stages $\left(P<2.2 \times 10^{-16}\right)$; PC1 also showed a difference in early lactation and in the dry period $(P<2.2 \times$ $\left.10^{-16}\right)$. The scores of the first $3 \mathrm{PC}$ are plotted in Figure 1 as contour plots at each lactation stage. These plots summarize blood components related to protein metabolism, energy metabolism, liver function, and mineral metabolism, and they imply that the physiological status of the cows has changed during the past 2 decades. Table 6 shows the loadings of the $4 \mathrm{PC}$; for example, in early lactation, $\mathrm{PC} 1$ is given (approximately) by -0.37 BUN -0.45 T-CHOL $-0.45 \mathrm{Mg}-0.45 \mathrm{ALB}+0.45$ GLOB (ignoring the factors with loadings of $<0.30$ in absolute value). The loadings were used to explain what each PC means, such as increasing negative energy balance and liver dysfunction. The contribution of the 12 components to each of the $4 \mathrm{PC}$ in each lactation stage and dry period is given in Table A1. This table can be used to estimate the effect of each blood components to each PC; for example, in early lactation, PC1 increases by 0.07 when HT increases by 1 .

\section{DISCUSSION}

Table 4 shows that indicators of energy metabolism (NEFA) and liver function (AST) have increased great- 
Table 4. Summary of the 12 components (mean with SD in parentheses) in each period and lactation stage

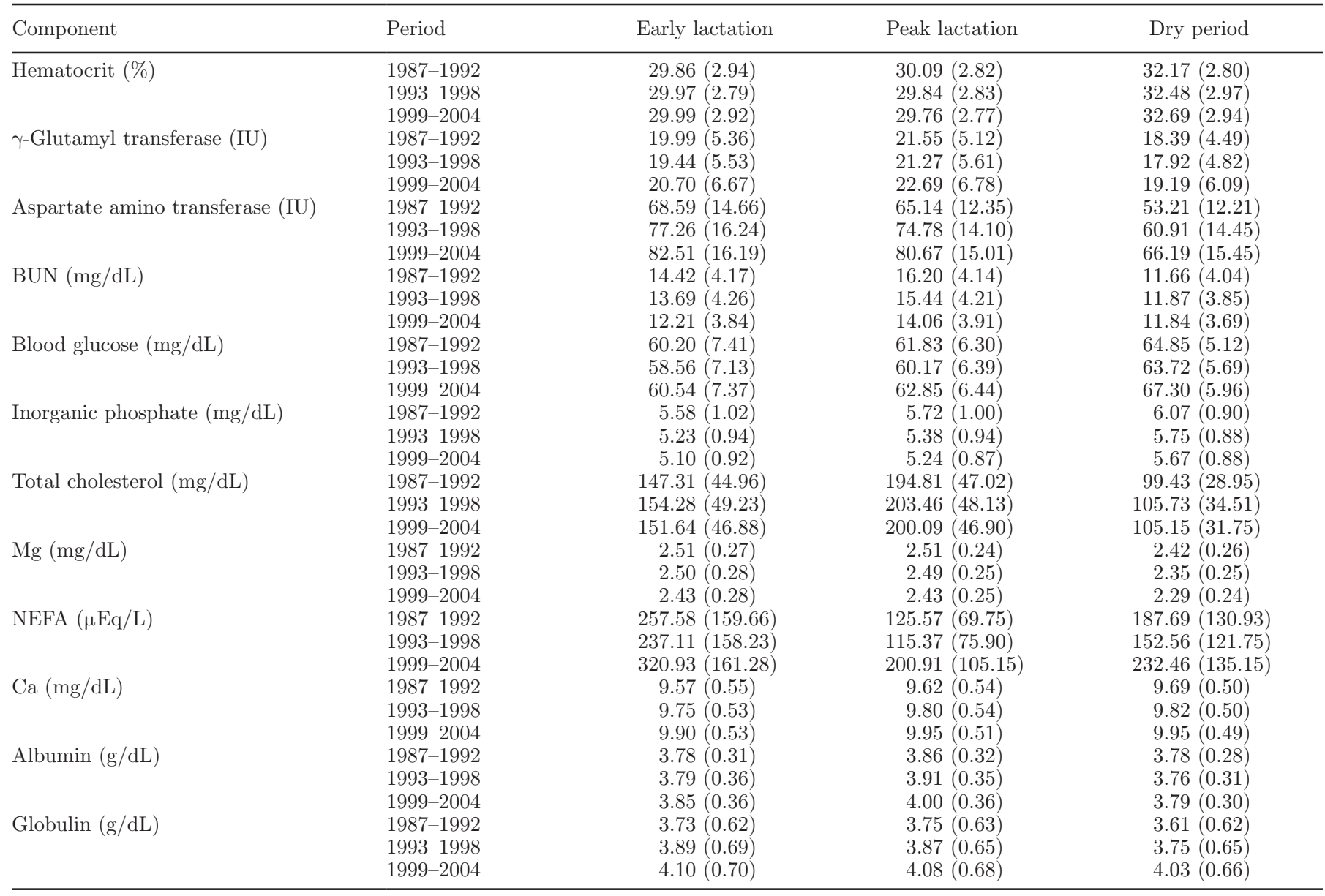

ly during the past 2 decades. The increase in NEFA in this study indicates that cows might be experiencing increasing negative energy balance and energy deficiency, particularly in peak lactation, because NEFA is a direct measure of fat mobilization (e.g., Andrews, 2000), and an increase in NEFA indicates a basic energy deficiency and a negative energy balance of the cow (Kida, 2003). The increase in AST shows that cows might be suffering from liver dysfunction in all 3 lactation stages, because AST is used as an indicator of liver function. In particular, high AST activity can be a measure of hepatic lipidosis (González et al., 2011) and the presence of fatty liver (Cavestany et al., 2005). Other physiological states of cows may be changed during the past 2 decades according to slight differences in indicators of protein metabolism, energy metabolism, liver function, and mineral metabolism.

One of the most important aspects of PCA is interpretation of each PC based on the loadings. Such interpretation reveals alterations in metabolic profiles across the multiyear periods, reflecting the changes in the physiological status of the cows. Table 5 (a summa- ry of the first $4 \mathrm{PC}$ in early and peak lactation and dry period) shows that PC2 and PC3 were much different across multiyear periods at all stages $\left(P<2.2 \times 10^{-16}\right)$. Main blood components contributing to $\mathrm{PC} 2$ and $\mathrm{PC} 3$ were NEFA and AST, together with some indicators of liver function (GGT), protein metabolism (GLOB), and mineral metabolism (IP). Principal component 1 also showed significant difference in early lactation and the dry period $\left(P<2.2 \times 10^{-16}\right)$. The main blood components of PC1 were indicators of energy metabolism (T-CHOL), mineral metabolism $(\mathrm{Mg})$, and protein metabolism (ALB and GLOB). However, the difference in $\mathrm{PC} 1$ was much lower than that in $\mathrm{PC} 2$ and $\mathrm{PC} 3$.

In early lactation, NEFA and AST were the top 2 components contributing to $\mathrm{PC} 2$. Increases in NEFA and AST resulted in a decrease of $\mathrm{PC} 2$, because the loadings of NEFA and AST to PC2 were -0.51 and -0.47 ; this means that $\mathrm{PC} 2$ is given, approximately, by $\mathrm{PC} 2=-0.51 \mathrm{NEFA}$ and $-0.47 \mathrm{AST}$ (ignoring components with loadings of $<0.40$ in absolute value). The actual contribution of NEFA and AST to PC2 is given in Table A1, which shows the change of each PC 
reflected by the unit increase $(+1)$ of each component. The decrease in PC2 across multiyear periods in this study means that the cows are probably experiencing increasing liver dysfunction, negative energy balance, and severe energy deficiency, because as we described above, an increase in NEFA indicates that cows might be experiencing increasing negative energy balance and energy deficiency, and an increase in AST shows that the cows might be suffering from liver dysfunction. In addition, PC3 was approximately given by PC3 = -0.54 GLOB and -0.48 GGT; PC3 probably indicates that increasing chronic inflammation and liver dysfunction has occurred in cows during the past 2 decades in Japan (because GLOB is an immunoglobulin and its increase in cows implies chronic inflammation; e.g., Andrews, 2000). High GGT would be the result of liver dysfunction, which shows that the health status of the cows has declined: in fact, Mudron et al. (1999) reported that significantly higher serum activity of GGT $(P<0.05)$ was observed in cows with liver failure, although González et al. (2011) has shown that AST is more sensitive than GGT for detecting hepatic lesions.

At peak lactation, NEFA and AST contributed greatly to $\mathrm{PC} 2$ with loadings of -0.46 and -0.37 , respectively. Inorganic phosphate and GLOB were also effective components of PC2 with loadings of 0.43 and -0.35 , respectively. Principal component 2 showed that cows were probably experiencing increasing liver dysfunction, negative energy balance, energy deficiency, and chronic inflammation according to high NEFA, AST, and GLOB values; the cause of the decrease in IP, likely indicating a decrease in intake of dietary phosphorus (Kida, 2003), was not clarified in this study. The main component contributing to PC3 was GLU $(-0.72)$, although there was smaller difference in PC3 than in PC2 (Table 5). A higher PC3 score was obtained by reflecting the decrease of GLU in the second period of 1993-1998 (Tables 4 and 5). Principal component 3 might reflect the existence of disorders such as ketosis and infertility and low energy intake in 1993-1998 according to the interpretation of hypoglycemia by Payne and Payne (1987) and Kida (2003). These problems might be caused by the progeny test popularized in farms around 1990 to breed high-producing dairy cows in Japan.

In the dry period, $\mathrm{PC} 2$ was obtained by $-0.53 \mathrm{AST}$, -0.45 GGT, and -0.44 GLOB (ignoring components with loadings of $<0.40$ in absolute value). Principal component 2 shows that the cows were probably experiencing increasing liver dysfunction (high AST and GGT) and chronic inflammation (high GLOB). Principal component 3 indicates increasing negative energy balance and energy deficiency. A lower PC3 score was obtained in the third multiyear period (1999-2004) and is probably reflected by a much higher NEFA concentration (Tables 4 and 5). In fact, the component contributing most to PC3 was NEFA (loading of -0.55) in the PCA result. Although BUN, an indicator of protein

Table 5. Summary of the first 4 principal components (PC) at early and peak lactation stages and in the dry period

\begin{tabular}{|c|c|c|c|c|c|}
\hline Item & $\mathrm{PC} 1$ & $\mathrm{PC} 2$ & PC3 & $\mathrm{PC} 4$ & Total \\
\hline
\end{tabular}

${ }^{1} P$-values indicate the significance of the difference between 3 mean values on each PC by Kruskal-Wallis test. The $\chi^{2}$ values show the test statistic values of the Kruskal-Wallis test. A large $\chi^{2}$ value results in a small $P$-value. The means (SD in parentheses) of each PC at each year stage are also shown. 
Early
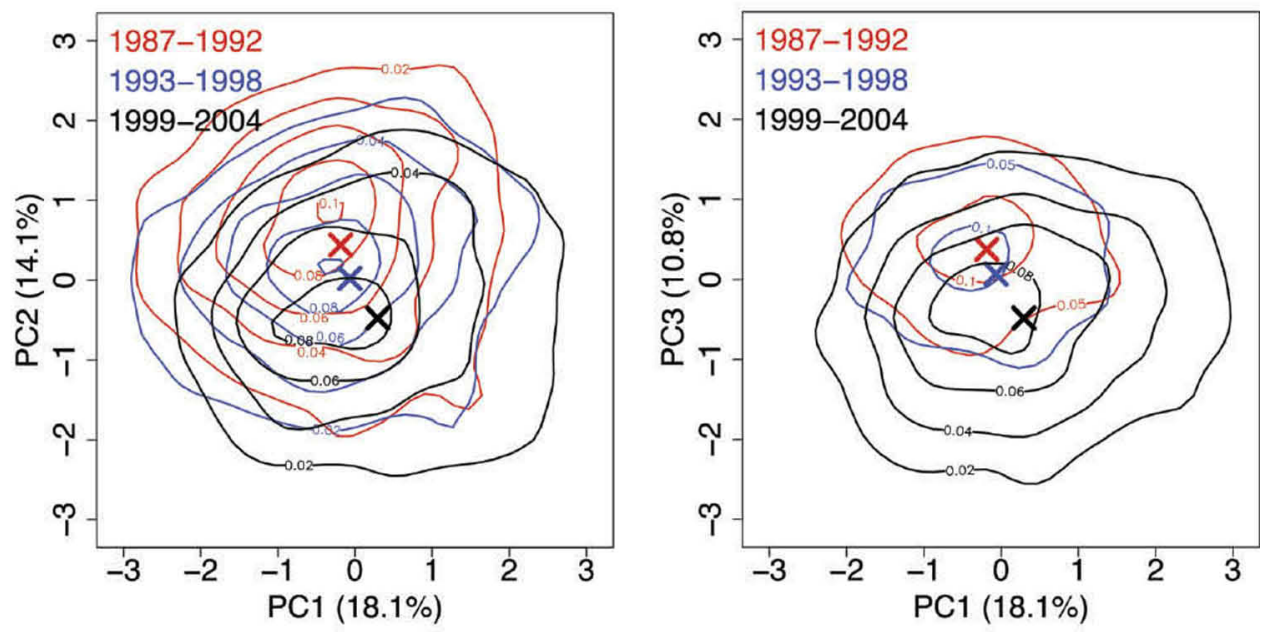

Peak
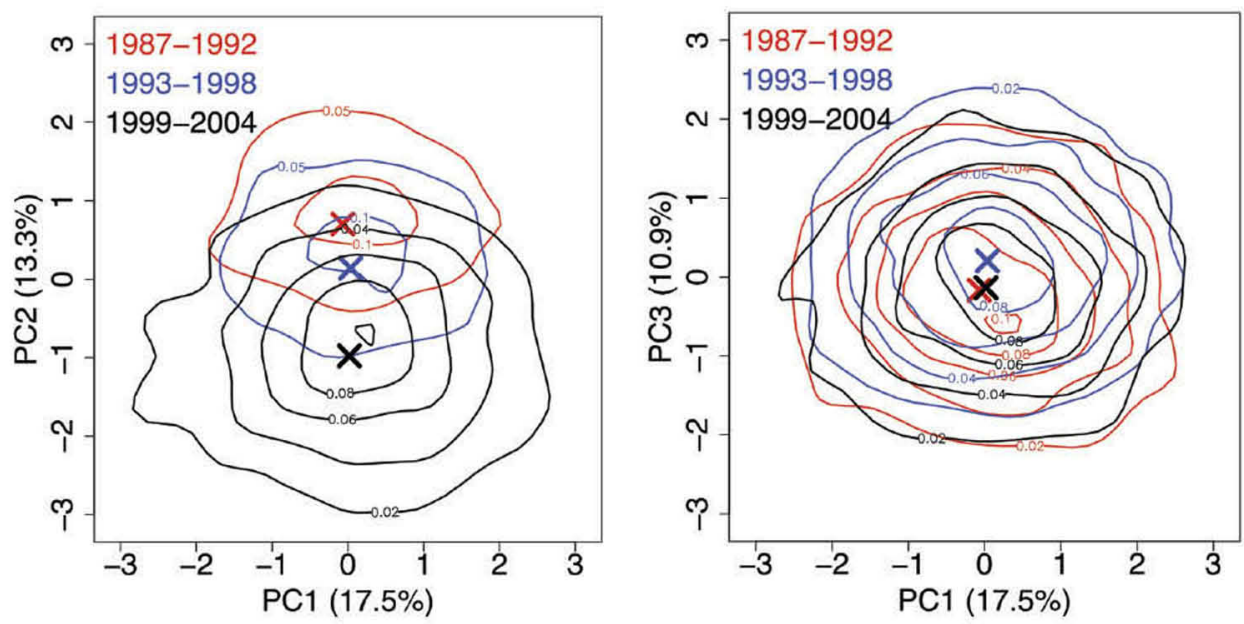

Dry period
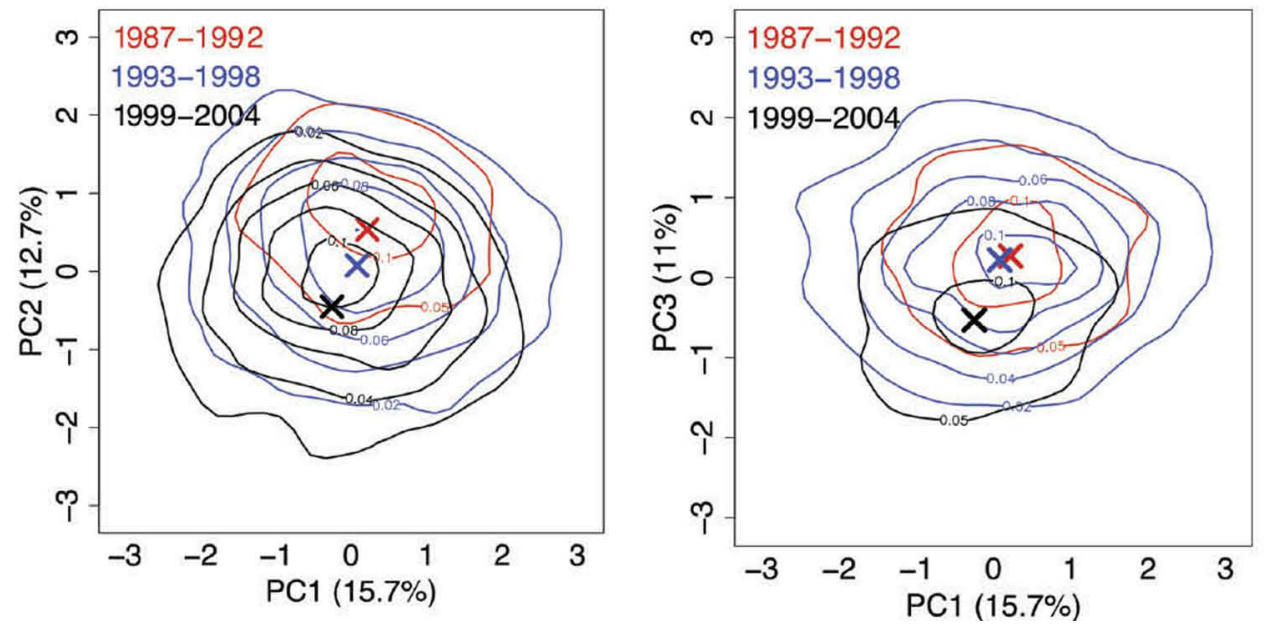

Figure 1. Contour plots of the first 3 principal components $(\mathrm{PC})$ in the early $(\mathrm{n}=5,144)$ and peak $(\mathrm{n}=8,027)$ lactation stages and the dry period $(\mathrm{n}=6,492)$, colored according to multiyear periods: 1987-1992 (red), 1993-1998 (blue), and 1999-2004 (black). The first 3 PC show significant difference between multiyear period. Crosses $(x)$ indicate the mean value of each PC; lines represent contour lines for the pair of PC at each stage of the year. 
Table 6. Loadings of the first 4 principal components (PC) at early and peak lactation stages and in the dry period ${ }^{1}$

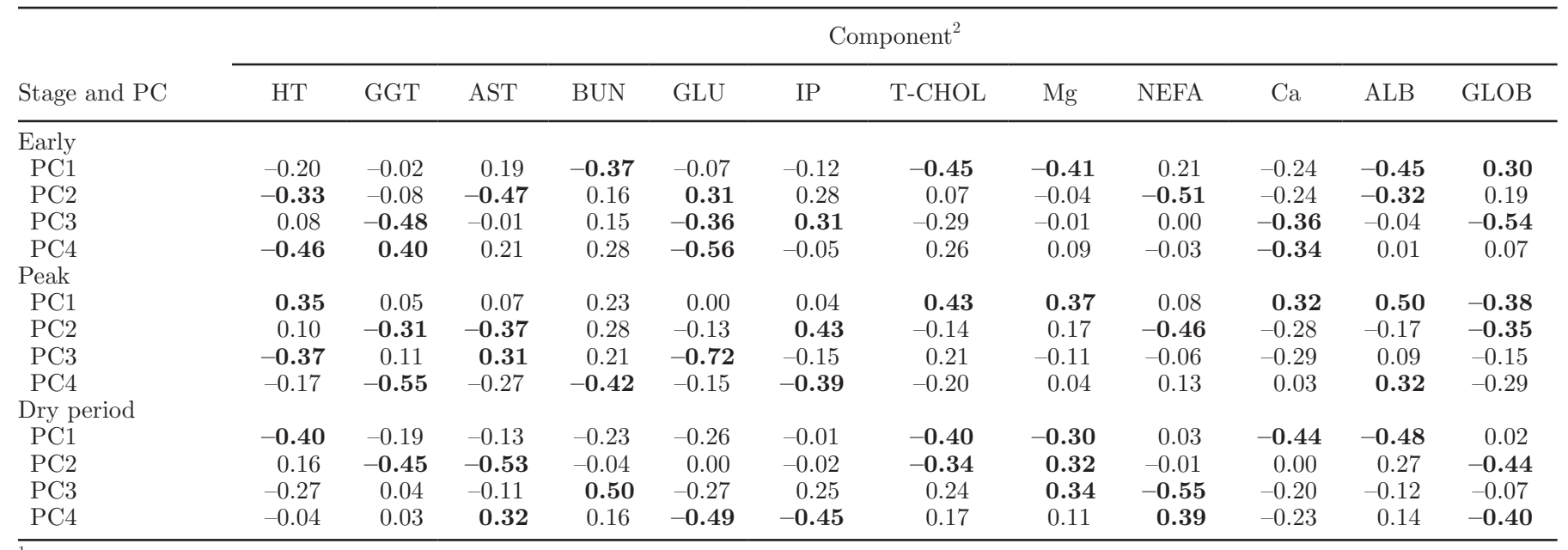

${ }^{1}$ For example, in early lactation, PC1 is given approximately by -0.37 BUN -0.45 T-CHOL $-0.41 \mathrm{Mg}-0.45$ ALB + 0.30 GLOB by ignoring factors with an absolute value of loading $<0.30$ (values in boldface $=$ absolute value $>0.30$ ).

${ }^{2} \mathrm{HT}=$ hematocrit; GGT $=\gamma$-glutamyl transferase; AST $=$ aspartate amino transferase; GLU = blood glucose; IP = inorganic phosphate; $\mathrm{T}-\mathrm{CHOL}=$ total cholesterol; $\mathrm{ALB}=$ albumin; $\mathrm{GLOB}=$ globulin .

metabolism (e.g., Kida, 2003), had a large loading in absolute value $(-0.50)$, it did not seem to be an effective component to PC3, because a slight increase occurred in the dry period (Table 4 ).

In summary, PC2 and PC3 were very different across multiyear periods in all stages of lactation $(P<2.2 \times$ $\left.10^{-16}\right)$. This difference in PC2 and PC3 implies that cows were probably experiencing increasing negative energy balance, energy deficiency, and liver dysfunction. This insight was supported not only by the single change of NEFA and AST (Table 4) but also by simultaneous analysis by PCA of the 12 blood components. In general, problems such as liver dysfunction and negative energy balance are likely contributors to infertility in high-producing dairy cows (e.g., Butler and Smith, 1989; Butler, 2005). The most effective and essential approach to remedying these problems may be the design of feeding systems to prevent rumen acidosis and maintain liver health (e.g., Kida, 2002a).

\section{CONCLUSIONS}

We investigated changes in the metabolic profile in each lactation stage between 3 multiyear periods (1987-1992, 1993-1998, and 1999-2004). We divided the cows into groups based on 3 multiyear periods and 5 lactation stages (including the dry period), and PCA was applied to the long-term metabolic profiles separately in each lactation stage. The application of PCA showed that the cows have probably experienced increasing negative energy balance, severe energy deficiency, and liver dysfunction over the past 2 decades in Japan. This insight was supported not only by a single change of each blood component but also by simultaneous analysis by PCA of 12 blood components.

\section{ACKNOWLEDGMENTS}

The metabolic profile tests were conducted at the Agricultural Mutual Aid Association (NOSAI; Hokkaido, Japan). The authors especially thank the animal doctors at NOSAI and farmers in Hokkaido for their help in this study. This study was supported, in part, by Grant-in-Aid for Young Scientists 24700290 from the Ministry of Education, Culture, Sports, Science and Technology (MEXT) in Japan.

\section{REFERENCES}

Adams, R. S., W. L. Stout, D. C. Kradel, S. B. Guss Jr., B. L. Moser, and G. A. Jung. 1978. Use and limitations of profiles in assessing health or nutritional status of dairy herds. J. Dairy Sci. 61:16711679 .

Andrews, A. H. 2000. The Health of Dairy Cattle. Blackwell Science Ltd., Ames, IA.

Butler, W. R. 2005. Relationships of negative energy balance with fertility. J. Adv. Dairy Res. 17:35-46.

Butler, W. R., and R. D. Smith. 1989. Interrelationships between energy balance and postpartum reproductive function in dairy cattle. J. Dairy Sci. 72:767-783.

Cavestany, D., J. E. Blanc, M. Kulcsar, G. Uriarte, P. Chilibroste, A. Meikle, H. Febel, A. Ferraris, and E. Krall. 2005. Studies of the transition cow under a pasture-based milk production system: Metabolic profiles. J. Vet. Med. A Physiol. Pathol. Clin. Med. 52:1-7.

Eicher, R. 2003. Metabolic profile testing in dairy herds: Wrong answer or wrong question? Acta Vet. Scand. 44(Suppl. 98):203. (Abstr.)

González, F. D., R. Muino, V. Pereira, R. Campos, and J. L. Benedito. 2011. Relationship among blood indicators of lipomobilization and hepatic function during early lactation in high-yielding dairy cows. J. Vet. Sci. 12:251-255. 
Holtenius, K., K. P. Waller, B. E. Gustavsson, P. Holtenius, and C. H. Sandgren. 2004. Metabolic parameters and blood leukocyte profiles in cows from herds with high or low mastitis incidence. Vet. J. 168:65-73.

Kaneko, J. J. 1989. Clinical Biochemistry of Domestic Animals. Academic Press Inc., San Diego, CA.

Kida, K. 2002a. The metabolic profile test: Its practicability in assessing feeding management and periparturient diseases in high yielding commercial dairy herds. J. Vet. Med. Sci. 64:557-563.

Kida, K. 2002b. Use of every ten-day criteria for metabolic profile test after calving and dry off in dairy herds. J. Vet. Med. Sci. 64:1003-1010.

Kida, K. 2003. Relationships of metabolic profiles to milk production and feeding in dairy cows. J. Vet. Med. Sci. 65:671-677.

Kudlác, E., M. Sakour, and J. Canderie. 1995. Metabolic profile in cows in the peripartum period with and without retained placenta. Vet. Med. (Praha) 40:201-207.

Lee, A. J., A. R. Twardock, R. H. Bubar, J. E. Hall, and C. L. Davis 1978. Blood metabolic profiles: their use and relation to nutritional status of dairy cows. J. Dairy Sci. 61:1652-1670.
Macrae, A. I., D. A. Whitaker, E. Burrough, A. Dowell, and J. M. Kelly. 2006. Use of metabolic profiles for the assessment of dietary adequacy in UK dairy herds. Vet. Rec. 159:655-661.

Mudron, P., J. Rehage, K. Qualmann, H. P. Sallmann, and H. Scholz. 1999. A study of lipid peroxidation and vitamin $\mathrm{E}$ in dairy cows with hepatic insufficiency. Zentralbl Veterinarmed A 46:219-224.

NRC. 2001. Nutrient Requirements of Dairy Cattle. 7th ed. National Academies Press, Washington, DC.

Payne, J. M. 1972. The Compton metabolic profile test. Proc. R. Soc. Med. 65:181-183.

Payne, J. M., S. M. Dew, R. Manston, and M. Faulks, 1970. The use of a metabolic profile test in dairy herds. Vet. Rec. 87:150-158.

Payne, J. M., and S. Payne. 1987. The Metabolic Profile Test. Oxford University Press, Oxford, UK.

Rowlands, G. J. 1984. Week-to-week variation in blood composition of dairy cows and its effect on interpretations of metabolic profile tests. Br. Vet. J. 140:550-557.

Stengärde, L., M. Traven, U. Emanuelson, K. Holtenius, J. Hultgren, and R. Niskanen. 2008. Metabolic profiles around calving in five high-producing Swedish dairy herds with a history or abomasal displacement and ketosis. Acta Vet. Scand. 50:31.

\section{APPENDIX}

Table A1. The contribution of the 12 components to each of the first 4 principal components (PC) at early and peak lactation stages and dry period $^{1}$

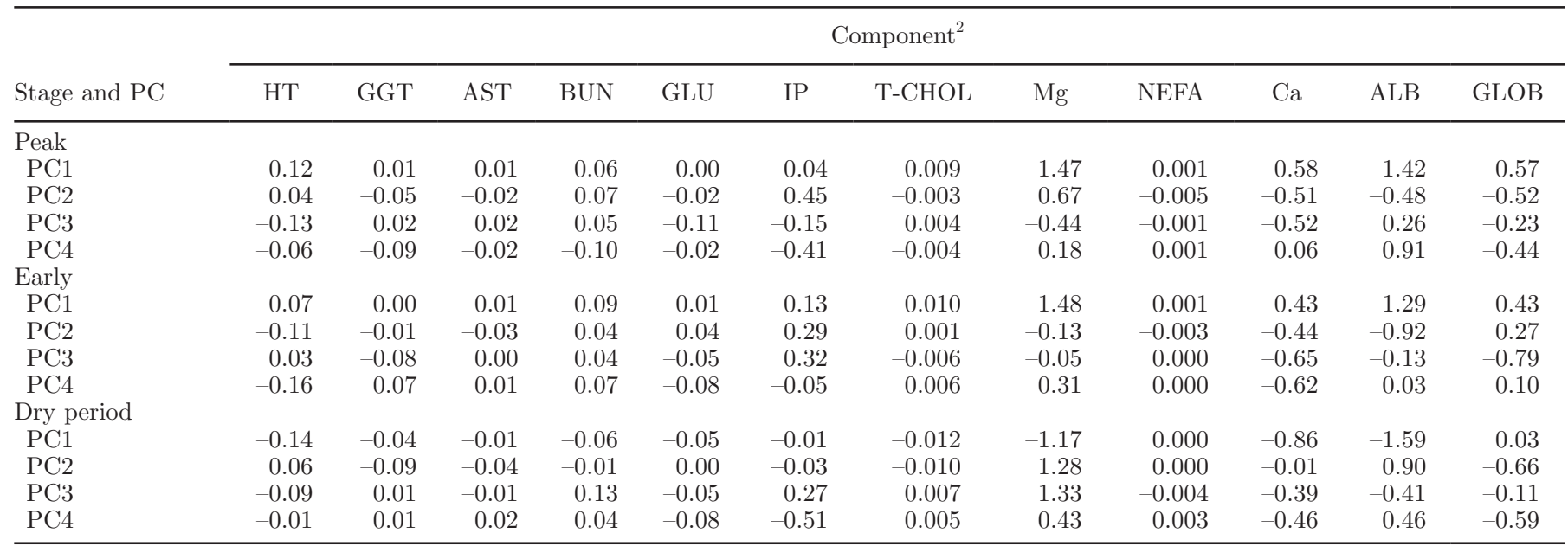

${ }^{1}$ For example, in early lactation, PC1 increased by 0.07 when HT increased by 1 .

${ }^{2} \mathrm{HT}=$ hematocrit; GGT $=\gamma$-glutamyl transferase; AST $=$ aspartate amino transferase; GLU $=$ blood glucose; IP $=$ inorganic phosphate; $\mathrm{T}-\mathrm{CHOL}=$ total cholesterol; $\mathrm{ALB}=$ albumin; $\mathrm{GLOB}=$ globulin. 

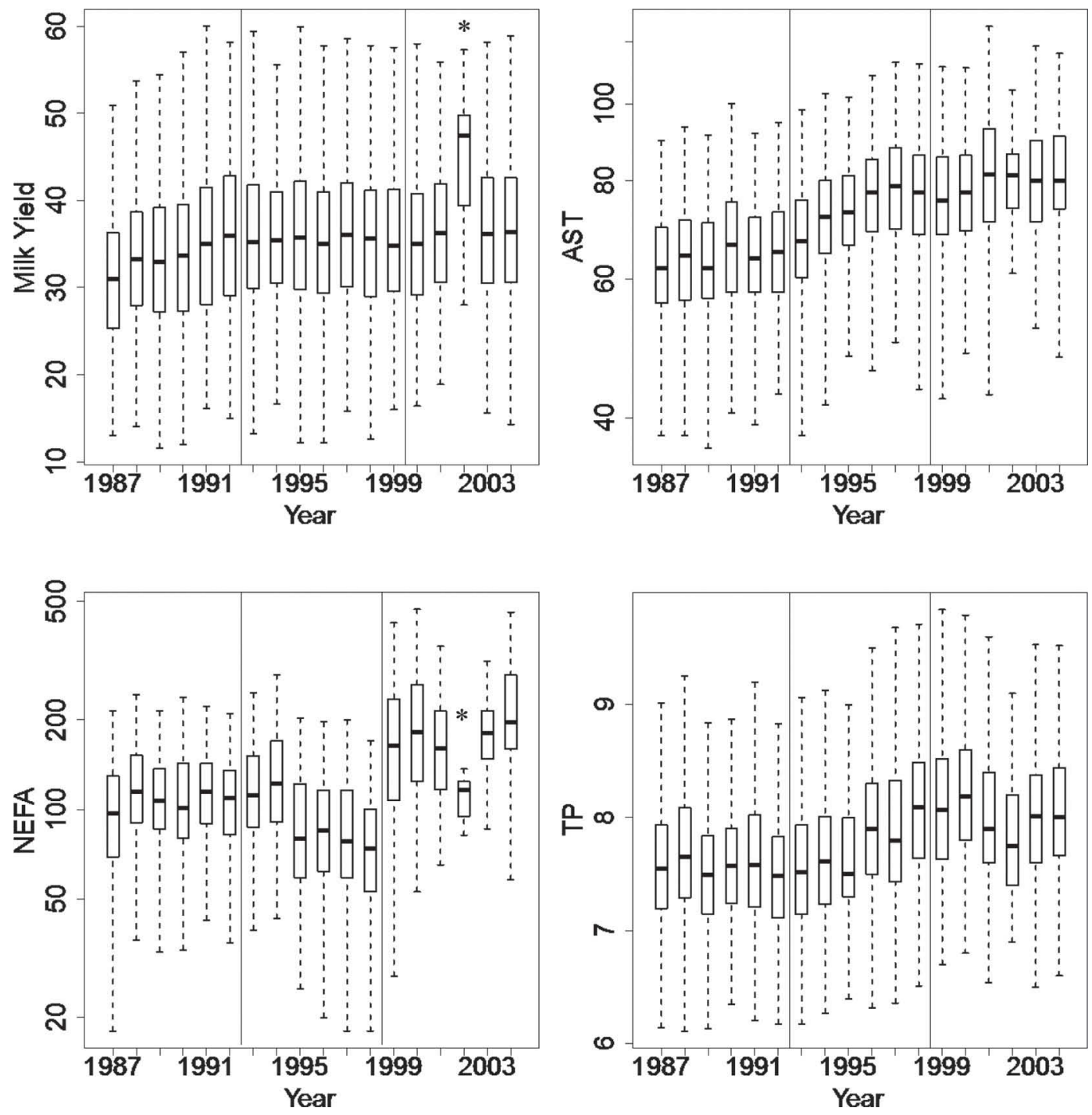

Figure A1. Yearly boxplots of milk yield, aspartate amino transferase (AST), NEFA, and total protein $(\mathrm{TP})$ at peak lactation $(\mathrm{n}=8,027)$. In 2002, there were only 18 cows, likely explaining the high and low values in milk yield and NEFA, respectively. The box represents the first and third quantiles of the data, with the second quantile (median) shown by the heavy line. The whiskers represent $2 \times \mathrm{SD}$ of the data. 

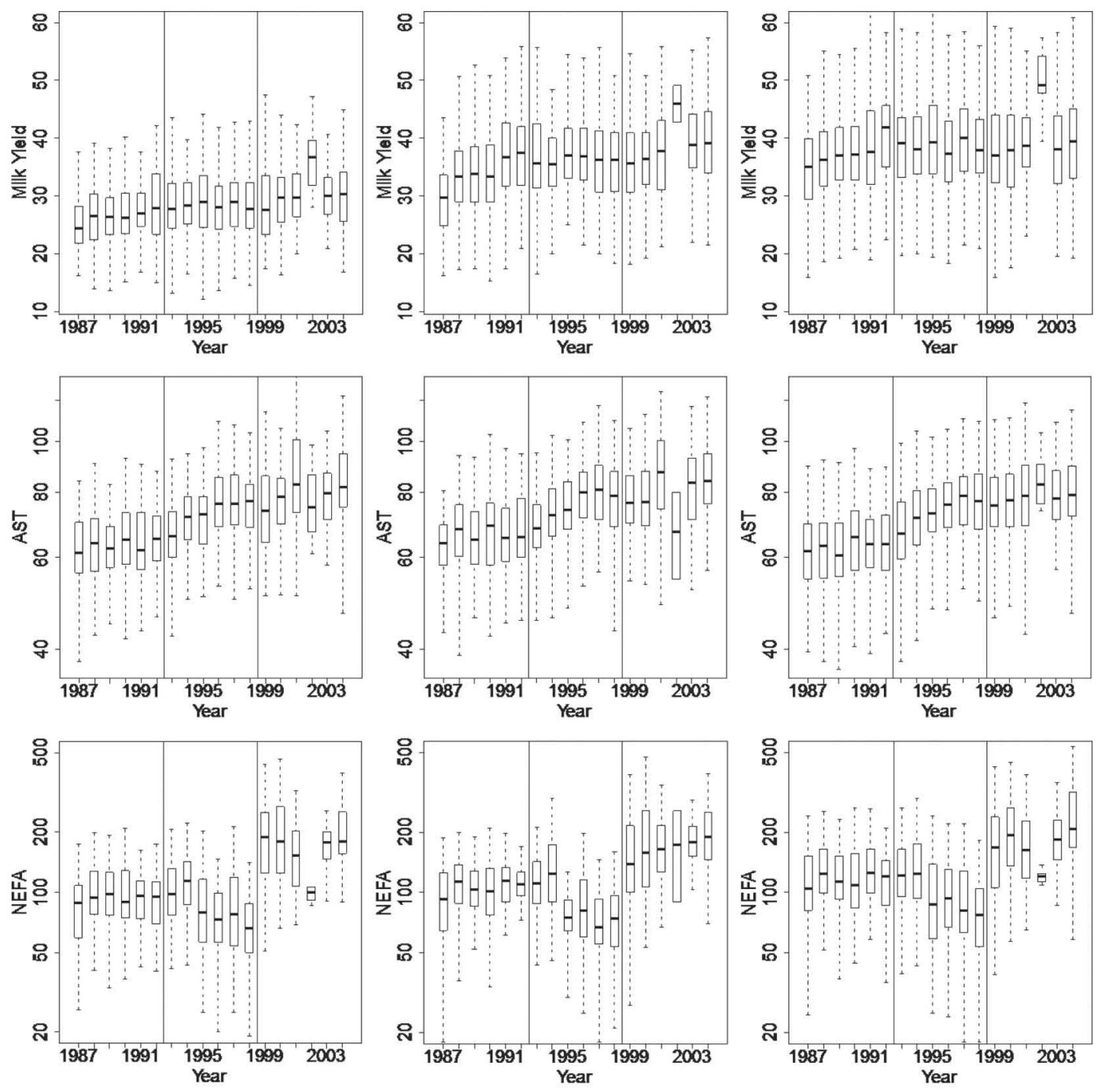

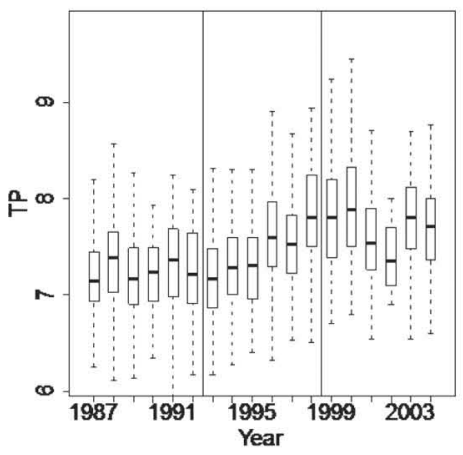

(1) First calving

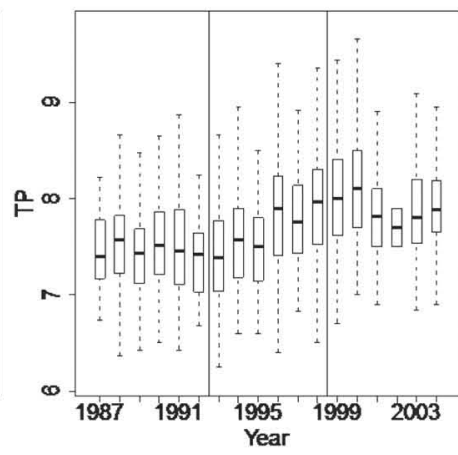

(2) Second calving

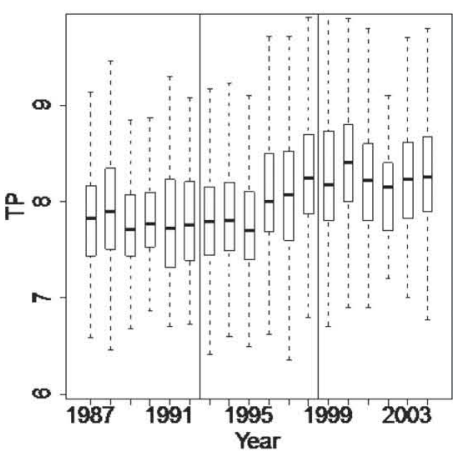

(3) $\geqq$ Third calving

Figure A2. Yearly boxplots of milk yield, aspartate amino transferase (AST), NEFA, and total protein (TP) at peak lactation stage (n = $8,027)$ divided by parity: (1) first $(\mathrm{n}=1,984)$, (2) second $(\mathrm{n}=2,036)$, and $(3) \geq$ third calving $(\mathrm{n}=4,007)$. The box represents the first and third quantiles of the data, with the second quantile (median) shown by the heavy line. The whiskers represent $2 \times \mathrm{SD}$ of the data. 

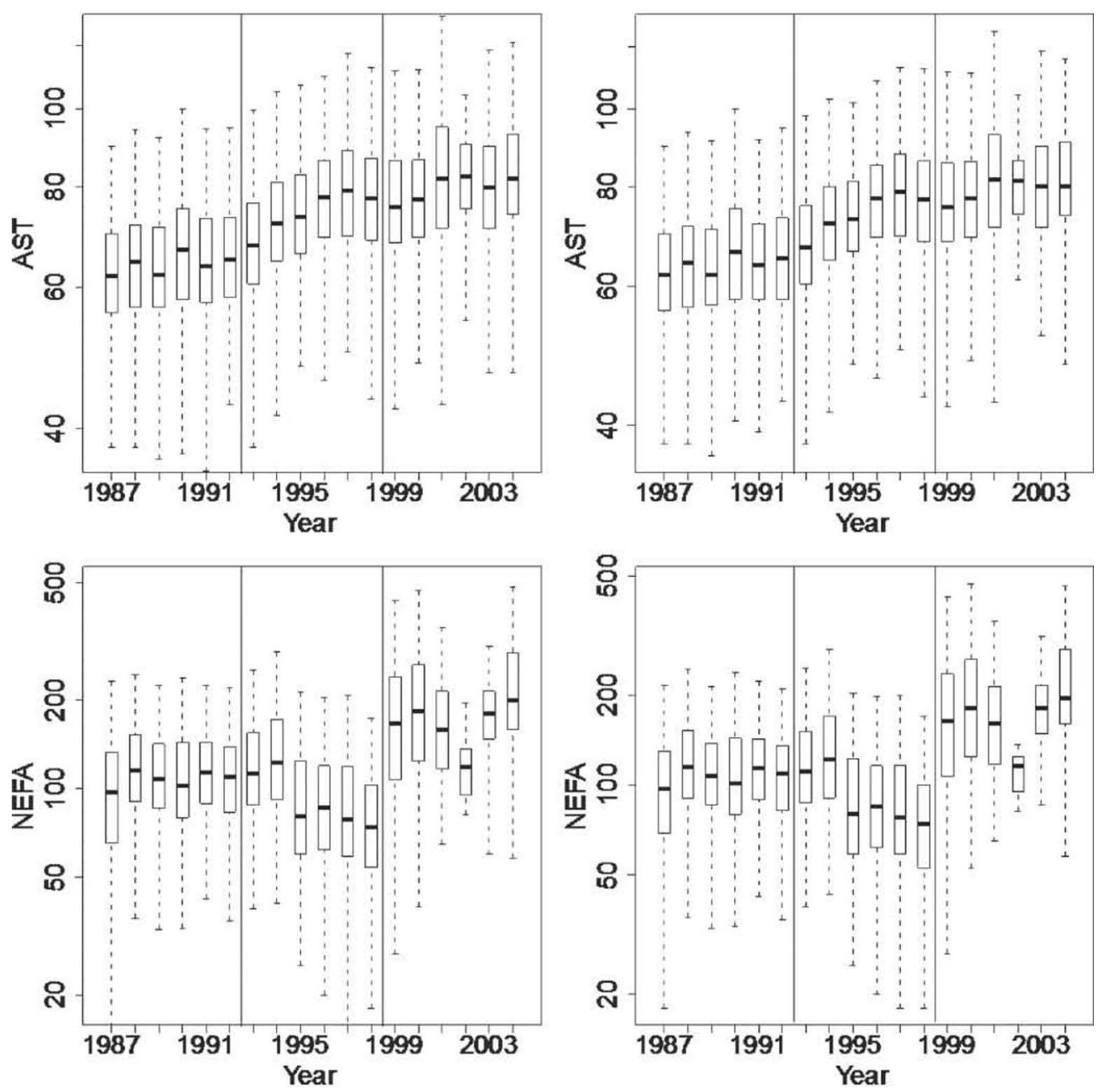

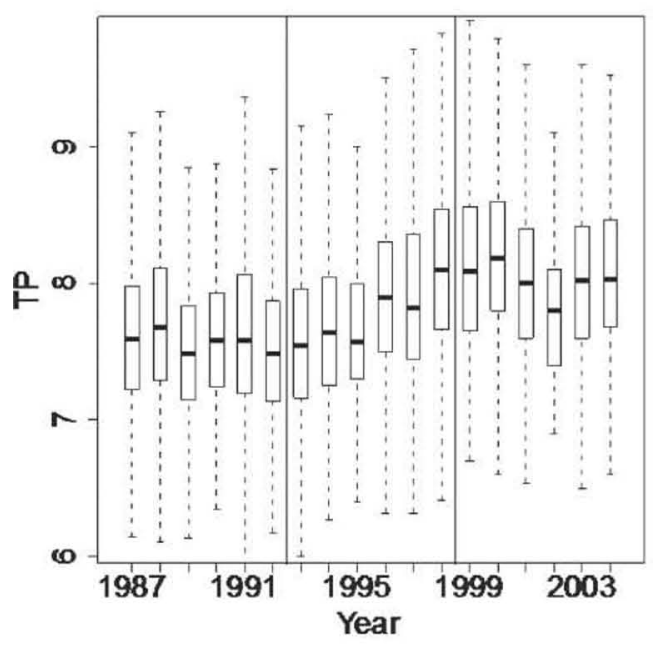

(1) with the outliers $(\mathrm{n}=8,927)$

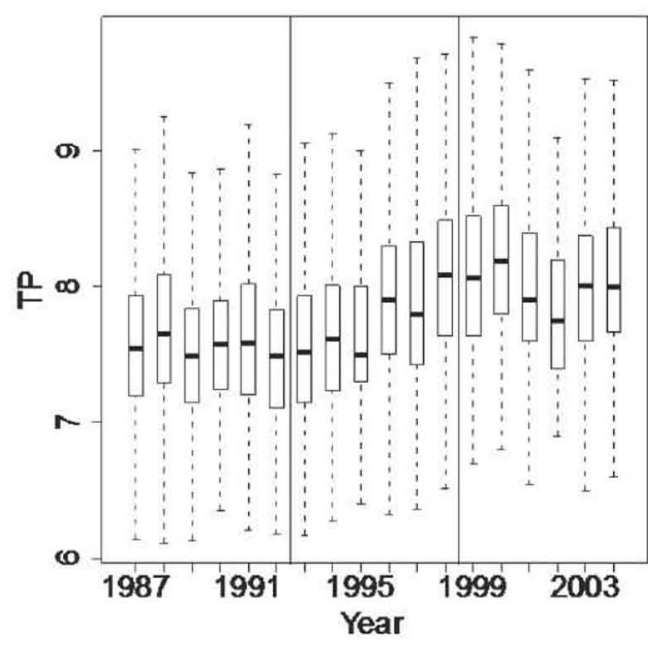

(2) without the outliers $(\mathrm{n}=8,027)$

Figure A3. Yearly boxplots of aspartate amino transferase (AST), NEFA, and total protein (TP) at peak lactation stage with $(\mathrm{n}=8,927)$ and without outliers $(\mathrm{n}=8,027)$, respectively. The box represents the first and third quantiles of the data, with the second quantile (median) shown by the heavy line. The whiskers represent $2 \times \mathrm{SD}$ of the data. 